\title{
Caregiver's burden in pulmonary arterial hypertension: a clinical review
}

\author{
Sameer Verma ${ }^{1,2}$, Abhineet Sayal', V. K. Vijayan ${ }^{3}$, Syed M.Rizvi', Arunabh Talwar ${ }^{1,2, *}$ \\ 'Department of Pulmonary, Critical Care and Sleep Medicine, Northwell Health, New Hyde Park, NY, USA \\ ${ }^{2}$ Feinstein Institute for Medical Research, Manhasset, NY, USA \\ ${ }^{3}$ Indian Council of Medical Research (ICMR), Bhopal Memorial Hospital and Research Centre (ICMR) \& National Institute for Research in Environmental Health (ICMR), \\ Bhopal, India \\ ${ }^{4}$ Touro College, New York School of Career and Applied Studies, New York, NY, USA
}

Caregiver's burden is a multidimensional phenomenon affecting caregivers physically, emotionally and socially. It is critical to examine the burden of caregivers, because of the complex responsibility they have with their partners. There are relatively few studies that have examined factors linked with psychological burden amongst caregivers of pulmonary arterial hypertension (PAH) patients. Hence, it is pertinent to devel- op a good understanding of these factors and develop appropriate management strategies, modified to assist PAH caregivers.

Keywords: Caregiver, Burden, Chronic disease, Pulmonary arterial hypertension, Screening questionnaire

\section{INTRODUCTION}

Pulmonary arterial hypertension (PAH) is a complex and progressive disease which results in non specific symptoms such as shortness of breath, fatigue and peripheral edema (Galiè et al., 2009). Our knowledge and understanding of the pathological process has vastly improved over the past 30 years leading to the development of medications to slow disease progression, improve functional capacity and increase survival. Even after all these advances, the natural progression of disease can cause profound limitations which result in significant lifestyle changes, thereby affecting one's quality of life (QoL). The insidious onset of the PAH can be enormously demoralizing and concurrently exerting an adverse impact on various aspects of life. It compels patients to request assistance from others, regarding frequent office visits, medication administration and hands-on-care with various activities of daily living. Though there is literature regarding the psychological impact on PAH patients' QoL; information about its impact on their caregivers is limited.

\section{WHO ARE THE CAREGIVERS?}

A caregiver is defined as any person providing assistance to a person with debilitating condition (Family Caregiver Alliance, 2006). A caregiver could be a relative, a friend or a neighbor who provides assistance due to patient's limitations without any monetary compensation (National Alliance for Caregiving/AARP, 2004). Much of the caregiving responsibility falls on patient's spouse (National Alliance for Caregiving/AARP, 2004). As a caregiver they focus more time, energy and logistics on assisting partners with their activities of daily living, managing finances, nutritional support, shopping and assisting with medication (Collins and Swartz, 2011).

Effective communication is imperative in conveying information. Caregivers, habitually, have more intimate knowledge of patient's well being and concern than anyone else. Therefore, they can communicate efficiently with their partner's physician (Cohen, 2000). They can provide considerable information, thus, allowing physicians to formulate a clinical judgment and management plan
${ }^{*}$ Corresponding author: Arunabh Talwar (iD http://orcid.org/0000-0003-2290-7562 Department of Pulmonary, Critical Care and Sleep Medicine, Northwell Health, 410 Lakeville Rd, New Hyde Park, NY 11040, USA

Tel: +1-516-465-5400, Fax: +1-516-465-5454, E-mail: arunabhtalwar1@gmail.com Received: August 3, 2016 / Accepted: September 20, 2016
This is an Open Access article distributed under the terms of the Creative Commons Attribution Non-Commercial License (http://creativecommons.org/licenses/by-nc/4.0/) which permits unrestricted non-commercial use, distribution, and reproduction in any medium, provided the original work is properly cited. 
about patient's condition. Their ability to communicate constructively with physicians is vital for their partner's well being. In addition to being an advocate for patients, they are expected to have knowledge about the rapidly changing healthcare system. In some cases, caregivers serve as legal and medical guardians, making decisions that impact the patient's health; for example, hospice care or nursing home care.

Caregivers are often responsible for providing emotional support and encouragement to their partners. They serve with great strength and courage, yet there contributions are mainly overshadowed and they remain an indiscernible group. However, as of late, their commitments and enduring challenges are starting to be recognized. There is considerable ideological thinking that having a chronic disease poses a significant challenge to both patients and their caregivers alike, and is often referred to as caregiver's burden.

\section{CAREGIVER'S BURDEN}

Caregiver's burden is defined as a multidimensional interaction of physical, emotional and economical hardship experienced by the caregiver (Zarit et al., 1980). It has been under intense focus in numerous conditions such as Alzheimer disease (Iavarone et al, 2014), Cancer (Bevans and Sternberg, 2012), and Stroke (Scholte op Reimer et al., 1998). For many caregivers, a lack of understanding of the disease process is a main cause of concern (Adelman et al., 2014). Caregivers perceive that they are being entrusted with the responsibility without any specific training, support or any prior education. They are concerned about not having the necessary skills which are required for optimal care given to their partners. Creasy et al. (2013) conducted a study of 17 family caregivers of stoke patients and their interaction with physicians. The study found that caregivers felt very disconnected and ignored by physicians and there was a lack of communication between each other.

The physical demands of being a caregiver can result in neglecting their own health, thus putting themselves at an increased risk of having health problems. The physical stress can lead to increased fatigue, cumulative sleep disruption at night, increased blood pressure and elevated heart rate (Family Caregiver Alliance, 2006; Jensen and Given, 1993; Monin et al., 2010). Study by McCurry and Ter (1995) found that of the 168 family caregivers of dementia patients, $68 \%$ of them had problems initiating and maintaining sleep along with daytime fatigue. The physical stress can also cause caregivers to neglect their own personal health, maintain a poor diet, be disinclined at maintaining medical ap- pointments and indulge in harmful health behaviors (Burton et al., 2003). In turn, these can result in an increased utilization of healthcare resources and escalate health care expenditure.

Stress emerges as a prominent symptom regularly. Caregivers may have a sense of being under constant stress because of concerns regarding patient's deterioration overtime, overwhelming workload, and being judgmental about their own capabilities of being a caregiver. The stress of caregiving has been found to be an independent risk factor for an increase in mortality (Schulz and Beach, 1999). Schulz and Beach (1999) in a prospective study, looked at 4-year mortality rate of 392 caregivers and 427 noncaregivers, who were living with their spouses. The main finding of this study demonstrated a $63 \%$ increase in mortality of caregiver's when compared with noncaregiver (Schulz and Beach, 1999). The prolonged physical burden can have a profound effect on physical health leading to psychological symptoms and limited social activities.

As caregivers continue to experience high levels of burden, it can contribute to symptoms of depression. For caregivers, depression can emanate as they observe their recipient undergo their terrible and unfortunate ordeal. Caregiver's vulnerability to depression is moderated by the duration of caregiving, decline in recipient's health and emotional well being (Schulz et al., 1995). Caregivers of low socioeconomic status, older population (women) and those with limited support system, experience more psychological effects than younger and more resourceful caregivers (Pinquart, 2001; Schulz et al., 1995; Vitaliano et al., 2003). Denno et al. (2013) found increased risk of anxiety and depression in 153 caregivers of stroke patients. Moreover, depression was also related to an increase in utilization of psychotropic medication by caregivers (Denno et al., 2013). In effect, depression in caregivers can also serve as a predictor of discontinuation of care for the elderly population (Arai et al., 2001). Inevitably, the overall responsibility can also lead to restricted social engagements and sacrificing family relationships (Kasuya et al., 2000).

Aside from the physical and psychological manifestations, financial strain is a reason of major stress for caregivers (Nolan et al., 1990). Many caregivers are unable to balance their work and caregiving duties, resulting in significant loss of income and decreased productivity at work (Ganapathy et al., 2015). Caregivers are subjected to adjust their workload which can overlap with their responsibility towards their care recipient. In other instances, caregivers are compelled to work as part-time employees and in serious circumstances they resign in order to undertake more responsibilities. 
While caregiving can present with challenges, it is imperative not to ignore the positive aspects of this experience. Many caregivers find care giving to be very rewarding and a satisfying experience (Cohen, 2000). It gives caregivers profound sense of privilege, altruistic feeling and deep fulfillment in providing assistance. They strongly believe, that caregiving has provided them purpose in their lives and help them learn new skills along the way (Schulz et al., 1997). Lundh (1999) surveyed 123 caregivers by using Carer's assessment of satisfaction index. The survey found (95\%) of caregivers were satisfied with their life as a caregiver.

\section{PAH AND CAREGIVER'S BURDEN}

Caregiver's burden has been extensively studied in various conditions, but there remains lack of relevant data about association of caregiver's burden with PAH (Table 1). Hwang et al. (2011) focused on understanding the risk of depression and impact of caregiving among 35 caregivers and their recipient, by using a patient health questionnaire (PHQ-8), social support survey and a care- giver reaction assessment. The study found that a lack of emotional support played a big factor in the well being of family caregivers. In this study, lower levels of social support were associated with increased depression like symptoms in at least $14 \%$ of caregivers. Caregivers also felt the financial impact of responsibilities and perceived them to be a hindrance towards their own normal daily activities. These findings were consistent with caregivers of patients' with other chronic diseases (Hwang et al., 2011).

Another survey in the United States (US) was conducted to provide an insight of the lives of $79 \mathrm{PAH}$ patients and their 76 caregivers in US (Pulmonary Hypertension Association, 2013). In this survey, $62 \%$ of caregivers felt an overall significant impact on their daily lives, with caregivers assisting in administering medication (54\%), doing household chores (61\%) (Pulmonary Hypertension Association, 2013). Still majority of caregivers found this experience to be rewarding and believed that this ordeal brought them closer to their partner. The results from this US survey imply that a system of collaborative care, which includes caregivers, should be established to provide optimal care to PAH patients

Table 1. Major studies of caregiver's burden and PAH cohort

\begin{tabular}{|c|c|c|c|}
\hline Trial/year & Study design & No. & Results \\
\hline Hwang et al./2011 & Cross-sectional descriptive study & 35 Dyad of patients and family caregivers & $\begin{array}{l}\text { 14\% Caregivers moderate to severe depression } \\
\text { 80\% Caregivers lived with patient } \\
14 \% \text { Quit jobs } \\
54 \% \text { Available } 24 \text { hr/day } \\
91 \% \text { Attend appointment with health care provider } \\
\text { 86\% Obtain medication } \\
\text { 90\% Helped with household work }\end{array}$ \\
\hline PHA (USA)/2013 & Survey & $\begin{array}{l}79 \text { Patients } \\
76 \text { Caregivers }\end{array}$ & $\begin{array}{l}\text { Patients } \\
\text { Physical activity: } 8 / 10 \text { had difficulty } \\
\text { Social activity: } 92 \% \text { employment difficulty, 83\% traveling difficulty } \\
\text { Daily life: 83\% difficulty with chores, } 78 \% \text { difficulty with errands } \\
\text { Relationship: } 75 \% \text { had intimacy problems } \\
\text { Caregivers } \\
57 \% \text { Schedule family life around patients } \\
62 \% \text { Run errands } \\
54 \% \text { Helping with medications } \\
64 \% \text { Future worries } \\
21 \% \text { Personal health suffered } \\
20 \% \text { Ouit working } \\
51 \% \text { Felt isolated } \\
72 \% \text { Found new meaning of life } \\
54 \% \text { Found fulfillment being a caregiver } \\
\text { 83\% Contributed significantly to patient's life }\end{array}$ \\
\hline PHA (EUROPE)/2012 & Survey & $\begin{array}{l}326 \text { PAH patients } \\
129 \text { Caregivers }\end{array}$ & $\begin{array}{l}\text { 57\% Affected caregiver's daily living } \\
\text { 43\% Exhausted because of responsibility } \\
29 \% \text { Impacted caregiver's work } \\
\text { 85\% Patient's work affected } \\
\text { 73\% Patient finances affected } \\
\text { 35\% Caregiver finances affected }\end{array}$ \\
\hline
\end{tabular}

PHA, Pulmonary Hypertension Association. 
(Pulmonary Hypertension Association, 2013).

Similarly, a large scale survey was also conducted in Europe to provide new insight into the impact of $\mathrm{PAH}$ on patients and their caregivers in 326 patients and 129 caregivers (European Pulmonary Hypertension Association, 2012). Living with PAH patients, caregivers (57\%) found it to be a physically draining and it disrupted their other daily activities (European Pulmonary Hypertension Association, 2012). Nearly half of caregivers surveyed felt they were exhausted because of the additional demands from patients (European Pulmonary Hypertension Association, 2012). In dealing with PAH patients, can lead to significant financial burden, reduced work place productivity and reduced household income. Many caregivers and patients, similarly, felt a loss of intimacy and overcome with feeling of isolation; mainly as a result of little understanding of the disease process. Despite these obstacles, $\mathrm{PAH}$ caregivers described their experience to be rewarding, and felt closer to their family (European Pulmonary Hypertension Association, 2012). Similar to the US survey, the findings from this survey draws attention to the importance of psychological support to be included as part of the comprehensive standard of care for both patients and caregivers.

\section{CAREGIVER BURDEN ASSESSMENT}

It is essential to assess and screen the degree of burden associated with caregiving. Several validated questionnaires have been developed to understand the consequences of caring for an individual with a chronic disease (Table 2).

\section{Caregiver burden scale}

Caregiver burden scale is a self administered twenty two item scale that is separated into 5 domains: general strain, isolation, disappointment, emotional involvement, and environment (Elmståhl, 1996). All the items are scored from 1 (not at all) to 4 (often). The total burden is calculated with a mean of all twenty two items. The scale measures, the caregiver's health, psychological well being and psychosocial aspects of their lives.

\section{Zarit burden scale}

The Zarit burden scale is used for measuring subjective burden of caregivers. The scale tests burden associated with functional, behavioral and home environment aspects. The original 29 item scale was modified to 22 items, which was further modified to 12 items (Zarit, 1980). It is a 29 item self administered instrument

Table 2. Selected caregiver burden assessment scales

\begin{tabular}{|c|c|c|c|}
\hline Scale/Author & No. of items & Response options & Score \\
\hline $\begin{array}{l}\text { Caregiver burden scale/ } \\
\text { Elmståhl et al. (1996) }\end{array}$ & 22 & $\begin{array}{l}\text { Responses include: } \\
\text { Not at all } \\
\text { Seldom } \\
\text { Sometimes } \\
\text { Often }\end{array}$ & - \\
\hline $\begin{array}{l}\text { Zarit burden interview/ } \\
\text { Zarit et al. (1980) }\end{array}$ & 29 & $\begin{array}{l}\text { 4-Point Likert scale } \\
\text { Self-reporting questionnaire }\end{array}$ & $\begin{array}{l}\text { 0-21 Little or no burden } \\
\text { 21-40 Mild to moderate burden } \\
\text { 41-60 Moderate to severe burden } \\
\text { 61-88 Severe burden }\end{array}$ \\
\hline $\begin{array}{l}\text { Caregiver reaction assessment/ } \\
\text { Given et al. (1992) }\end{array}$ & 24 & $\begin{array}{l}\text { 4-Point Likert scale } \\
\text { Self-reporting questionnaire } \\
\text { Impact on Caregiver's self-esteem (7 items) } \\
\text { Financial problems ( } 3 \text { items) } \\
\text { Impact on health ( } 4 \text { items) } \\
\text { Lack of family support ( } 5 \text { items) } \\
\text { Impact on daily activities ( } 5 \text { itmes) }\end{array}$ & - \\
\hline $\begin{array}{l}\text { Caregiver stain index/ } \\
\text { Robinson (1983) }\end{array}$ & 13 & "Yes" or "No" format & $\geq 7$ Needs further assessment \\
\hline $\begin{array}{l}\text { Caregiving appraisal scale / } \\
\text { Lawton et al. (1989) }\end{array}$ & 47 & $\begin{array}{l}\text { 5-Point Likert scale } \\
\text { Self-reporting questionnaire } \\
\text { Subjective caregiving burden (13 items) } \\
\text { Impact of caregiving ( } 9 \text { items) } \\
\text { Caregiving satisfaction ( } 9 \text { items) } \\
\text { Caregiving/master ( } 12 \text { items) } \\
\text { Caregiving ideology ( } 4 \text { items) }\end{array}$ & $\begin{array}{l}\text { Higher Scores (positivity) } \\
\text { Lower Scores (negativity) }\end{array}$ \\
\hline
\end{tabular}


with scores between 0 (never) and 4 (nearly always). It has confirmed high validity and consistency with score ranging from 0 to 88 (Zarit, 1980).

\section{Caregiver strain index}

Caregiver strain index is a brief and easily self-administered thirteen question tool used to measure family caregiving concerns and comprises of their perception of caregiving (Robinson, 1983). Employment, financial, physical and social issues are some of the domains addressed by this index. It can be used by individuals of any age and those who are responsible for the patient. Each item is answered in a "Yes" or "No" format, with "1" point for "Yes" and " 0 " for "No." A total of seven or more is indicative of a more indepth analysis (Robinson, 1983).

\section{Caregiver reaction assessment}

Caregiver reaction assessment is a multidimensional self rating tool with 24 items used to measure both positive and negative reactions of family members that can occur overtime (Given et al., 1992). The instrument consists of five dimensions of caregiving that are: (a) daily activities ( 5 items) that measure impact of caregiving on daily basis; (b) financial problems ( 3 items) measures financial strain due to caregiving; (c) health problems (4 items) measures caregiver's physical deterioration; (d) self-esteem (7 items) only positive domain measuring self worth; (e) lack of family support (5 items) determines caregiver's sense of abandonment and lack of moral support. Each positive or negative measure is on a likert scale of 1.0 (strongly disagree) to 5.0 (strongly agree). A mean score from each subscale is generated ranging from 1.0 to 5.0. A higher score represents a stronger impact of either a negative or positive characteristic (Given et al., 1992).

\section{Caregiving appraisal scale}

Caregiving appraisal scale is a caregiver satisfaction survey intended to measure five factors of caregiving that are tabulated on 5-point scales ranging from 1.0 (strongly disagree) to 5.0 (strongly agree). It is a self-administered 47 items questionnaire measuring the positive, neutral, and negative appraisals that are linked to caregiving (Lawton et al., 1989). The five dimensions considered are: (a) caregiving satisfaction, (b) perceived caregiving impact, (c) caregiving mastery, (d) caregiving ideology, and (e) subjective caregiving burden. A higher score reflects positive feelings about caregiving and lower scores reflect negative feelings (Lawton et al., 1989).

\section{FUTURE DIRECTION}

As more elderly people are living longer, there is an increase fiscal demand to have sufficient caregivers as well. Therefore, it is pertinent for healthcare policy makers to explore and address the implications of chronic disease on caregivers. Effective public policies should be established in order to recognize the sacrifice caregivers make on a daily basis and reflect changes that can fully address the needs of the caregiver as they serve as a moral fiber to our aging society. In any aspect, it is the physical and mental well being of a caregiver that is a reflection of the overall well being of chronic disease patients.

The diagnosis of PAH can cause profound psychological and physical stress because of the inability to function effectively. Since many caregivers believe they are unprepared and unfamiliar of their partner's condition, it is possible to introduce interventions to educate caregivers about future expectations. Therefore, educating caregivers about the patient's disease and its implications is a first step in relieving some burden (Gillick, 2013). Many caregivers feel secure when physicians have an open and honest communication about their partner's condition (Fleming, 2003). As a physician, it is pertinent to observe that both the caregiver and patient are able to comprehend the progressive and chronic nature of the illness, because it can impact their decision making process in the future. In any circumstance, by listening to patients and caregivers, physicians have the ability to recognize 'at-risk' individuals for caregiver burden (Kasuya et al., 2000).

The office personnel also have a crucial role in clinical practice. Aside from running the office smoothly, they can provide moral support and the proper resources for caregivers to get information (Lynn, 2014). In most healthcare setting, nurses are the prime contact for patients and caregivers. Accordingly, they are well positioned to encourage, educate and motivate caregivers in taking control of circumstances.

With the burden of caregiving having a negative impact on their lives, the most important thing for caregivers to remember is that they are not alone. There are supportive interventions available to reduce caregiver burden (Cohen, 2000; Kasuya et al., 2000). Support groups are often used by patients to ease burden of disease and it possible to extend this service to caregivers as well. Support groups are a useful method to share caregiver's unique experiences and at the same time, create an environment for all caregivers to learn from each other.

Furthermore, respite care is a service available for caregivers who need a temporary relief from the daily challenges of caregiv- 
ing. Respite care refers to allowing transfer of care to places such as: in-home help service, adult day care center or overnight care center (Carretero, 2009). For working caregivers, employers can provide some assistance in relieving some burden by providing flexible hours and referral services such as employee assistance programs (Lynn, 2014).

Finally, military veterans and senior citizens are often appreciated for their services. They are frequently eligible for courtesy discounts from many business institutions. Caregivers should receive similar recognition as well. In moving forward towards an effective support system, it is possible to have similar concessions and services be extended to caregivers.

\section{CONCLUSIONS}

$\mathrm{PAH}$ is a complex disease. The impact of PAH goes further than impairment of health and functional ability. The difficulties faced by caregivers are dependent on progression of PAH. Daily challenges presented to caregivers can create uncertainty in terms of coping with the worsening of disease. It is important for physicians to be aware of the caregivers' attributes that can cause significant burden. More research is needed to establish what factors are detrimental to caregiving, as it will be the responsibility of clinicians to identify these "at risk" caregivers. By way of using these assessment tools, physicians well be in a better position to screen for vulnerable caregivers and provide education along with counseling. As a society, we are indebted to caregivers for making an invaluable contribution; therefore, it is appropriate to 'take care' of our caregivers.

\section{CONFLICT OF INTEREST}

No potential conflict of interest relevant to this article was reported.

\section{REFERENCES}

Adelman RD, Tmanova LL, Delgado D, Dion S, Lachs MS. Caregiver burden: a clinical review. JAMA 2014;311:1052-1060.

Arai Y, Sugiura M, Washio M, Miura H, Kudo K. Caregiver depression predicts early discontinuation of care for disabled elderly at home. Psychiatry Clin Neurosci 2001;55:379-382.

Bevans M, Sternberg EM. Caregiving burden, stress, and health effects among family caregivers of adult cancer patients. JAMA 2012;307:398403.
Burton LC, Zdaniuk B, Schulz R, Jackson S, Hirsch C. Transitions in spousal caregiving. Gerontologist 2003;43:230-241.

Carretero S, Garcés J, Ródenas F, Sanjosé V. The informal caregiver's burden of dependent people: theory and empirical review. Arch Gerontol Geriatr 2009;49:74-79.

Cohen CA. Caregivers for people with dementia. What is the family physician's role? Can Fam Physician 2000;46:376-380.

Collins LG, Swartz K. Caregiver care. Am Fam Physician 2011;83:13091317.

Creasy KR, Lutz BJ, Young ME, Ford A, Martz C. The impact of interactions with providers on stroke caregivers' needs. Rehabil Nurs 2013; 38:88-98.

Denno MS, Gillard PJ, Graham GD, DiBonaventura MD, Goren A, Varon SF, Zorowitz R. Anxiety and depression associated with caregiver burden in caregivers of stroke survivors with spasticity. Arch Phys Med Rehabil 2013:94:1731-1736.

Elmståhl S, Malmberg B, Annerstedt L. Caregiver's burden of patients 3 years after stroke assessed by a novel caregiver burden scale. Arch Phys Med Rehabil 1996;77:177-182.

European Pulmonary Hypertension Association. The impact of pulmonary arterial hypertension (PAH) on the lives of patients and carers: results from an international survey [Internet]. European Pulmonary Hypertension Association (PHA); 2012 [cited 2015 Jun 29]. Available from: www.phaeurope.org/wp-content/uploads/International-PAHpatient-and-Carer-Survey-Report-FINAL1.pdf.

Family Caregiver Alliance. Caregiver assessment: principles, guidelines and strategies for change. Report from a national consensus development conference [Internet]. San Francisco (CA): Family Caregiver Alliance; 2006. [cited 2015 Jun 29]. Available from: http://www.caregiver. org/caregiver/jsp/content/pdfs/v1_consensus.pdf.

Fleming DA. The burden of caregiving at the end-of-life. Mo Med 2003; 100:82-86.

Galiè N, Hoeper MM, Humbert M, Torbicki A, Vachiery JL, Barbera JA, Beghetti M, Corris P, Gaine S, Gibbs JS, Gomez-Sanchez MA, Jondeau G, Klepetko W, Opitz C, Peacock A, Rubin L, Zellweger M, Simonneau G; ESC Committee for Practice Guidelines (CPG). Guidelines for the diagnosis and treatment of pulmonary hypertension: the Task Force for the Diagnosis and Treatment of Pulmonary Hypertension of the European Society of Cardiology (ESC) and the European Respiratory Society (ERS), endorsed by the International Society of Heart and Lung Transplantation (ISHLT). Eur Heart J 2009;30:2493-2537.

Ganapathy V, Graham GD, DiBonaventura MD, Gillard PJ, Goren A, Zorowitz RD. Caregiver burden, productivity loss, and indirect costs associated with caring for patients with poststroke spasticity. Clin Interv Aging 2015;10:1793-1802. 
Gillick MR. The critical role of caregivers in achieving patient-centered care. JAMA 2013;310:575-576.

Given CW, Given B, Stommel M, Collins C, King S, Franklin S. The caregiver reaction assessment (CRA) for caregivers to persons with chronic physical and mental impairments. Res Nurs Health 1992;15:271-283.

Hwang B, Fleischmann KE, Howie-Esquivel J, Stotts NA, Dracup K. Caregiving for patients with heart failure: impact on patients' families. Am J Crit Care 2011;20:431-441.

Iavarone A, Ziello AR, Pastore F, Fasanaro AM, Poderico C. Caregiver burden and coping strategies in caregivers of patients with Alzheimer's disease. Neuropsychiatr Dis Treat 2014;10:1407-1413.

Jensen S, Given B. Fatigue affecting family caregivers of cancer patients. Support Care Cancer 1993;1:321-325.

Kasuya RT, Polgar-Bailey P, Takeuchi R. Caregiver burden and burnout. A guide for primary care physicians. Postgrad Med 2000;108:119-123.

Lawton MP, Kleban MH, Moss M, Rovine M, Glicksman A. Measuring caregiving appraisal. J Gerontol 1989;44:P61-71.

Lundh U. Family carers. 2: Sources of satisfaction among Swedish carers. Br J Nurs 1999;8:647-652.

Lynn J. Strategies to ease the burden of family caregivers. JAMA 2014; 311:1021-1022.

McCurry SM, Teri L. Sleep disturbance in elderly caregivers of dementia patients. Clin Gerontol 1995;16:51-66.

Monin JK, Schulz R, Martire LM, Jennings JR, Lingler JH, Greenberg MS. Spouses' cardiovascular reactivity to their partners' suffering. J Gerontol B Psychol Sci Soc Sci 2010;65B:195-201.

National Alliance for Caregiving/AARP. Caregiving in the U.S. [Internet]. Washington, DC: National Alliance for Caregiving/AARP; 2004 [cited 2015 Jun 29]. Available from: http://assets.aarp.org/rgcenter/il/us_caregiving_1.pdf.
Nolan MR, Grant G, Ellis NC. Stress is in the eye of the beholder: reconceptualizing the measurement of carer burden. J Adv Nurs 1990;15: 544-555.

Pinquart M. Correlates of subjective health in older adults: a meta-analysis. Psychol Aging 2001;16:414-426.

Pulmonary Hypertension Association. The Impact of pulmonary arterial hypertension (PAH) on the lives of patients and caregivers: Results from a US study [Internet]. Silver Spring (MD): Pulmonary Hypertension Association; c2015 [updated 2013 Mar 28; cited 2015 Jun 29]. Available from: http://www.phaonlineuniv.org/files/PHA\%20Pub_ Final\%203\%2028\%202013.pdf.

Robinson BC. Validation of a caregiver strain index. J Gerontol 1983;38: 344-348.

Scholte op Reimer WJ, de Haan RJ, Rijnders PT, Limburg M, van den Bos GA. The burden of caregiving in partners of long-term stroke survivors. Stroke 1998;29:1605-1611.

Schulz R, Beach SR. Caregiving as a risk factor for mortality: the Caregiver Health Effects Study. JAMA 1999;282:2215-2219.

Schulz R, Newsom J, Mittelmark M, Burton L, Hirsch C, Jackson S. Health effects of caregiving: the caregiver health effects study: an ancillary study of the Cardiovascular Health Study. Ann Behav Med 1997;19:110-116.

Schulz R, O'Brien AT, Bookwala J, Fleissner K. Psychiatric and physical morbidity effects of dementia caregiving: prevalence, correlates, and causes. Gerontologist 1995;35:771-791.

Vitaliano PP, Zhang J, Scanlan JM. Is caregiving hazardous to one's physical health? A meta-analysis. Psychol Bull 2003;129:946-972.

Zarit SH, Reever KE, Bach-Peterson J. Relatives of the impaired elderly: correlates of feelings of burden. Gerontologist 1980;20:649-655. 